\title{
Facial Asymmetry
}

National Cancer Institute

\section{Source}

National Cancer Institute. Facial Asymmetry. NCI Thesaurus. Code C84702.

A finding indicating the absence of balanced proportions between parts of the face. 